\title{
Snoezelen Room and Childbirth Outcome: A Randomized Clinical Trial
}

\author{
Mansoureh Jamshidi Manesh ${ }^{1}$; Mahnaz Kalati ${ }^{2,}{ }^{*}$; Fatemeh Hosseini $^{3}$ \\ ${ }^{1}$ Department of Reproductive Health, Shahroud University of Medical Sciences, Shahoud, Iran \\ 2 Department of Reproductive Health, Shahroud University of Medical Sciences, Shahoud, Iran \\ ${ }^{3}$ Department of Biostatistics, School of Management and Medical Information, Iran University of Medical Sciences, Tehran, IR Iran \\ *Corresponding Author: Mahnaz Kalati, Labor and Childbirth Ward, Akbar Abadi Hospital, Iran University of Medical Sciences, Tehran, IR Iran. E-mail: mahnazkalati77@yahoo.com
}

Received: March 19, 2014; Revised: July 8, 2014; Accepted: September 2, 2014

\begin{abstract}
Background: One of the strategies for a good outcome and pain free childbearing is to design the delivery room.
Objectives: The aim of this study was to evaluate the effects of snoezelen room on childbearing outcome such as pain intensity, duration of labor, and perinea status in nulliparous women.

Patients and Methods: This study was a randomized controlled clinical trial consists of 100 childbearing women. They were randomly divided into 2 groups. The experimental group went to snoezelen room when their cervix dilation was $4 \mathrm{~cm}$, while the control group went to physiologic delivery room with the same cervix dilation.

Results: The mean \pm SD of VAS (Visual Analogue Scale) pain intensity of the experimental and control groups before the intervention were $5.1 \pm 1.95$ and $5.58 \pm 1.62$, respectively $(\mathrm{P}=0.13)$. The mean \pm SD of VAS pain intensity scores of the experimental and control groups after 3 hours spending in their assigned rooms were $5.26 \pm 0.86$ and $9.56 \pm 1.48$, respectively $(\mathrm{P}=0.01)$. The mean $\pm \mathrm{SD}$ of the first stage scores of the experimental and control groups were $6.95 \pm 0.97$ and $8.41 \pm 0.67$, respectively $(\mathrm{P}=0.042)$. About $92 \%$ of participants' intervention vs. $66 \%$ of control participants had perinea laceration $(\mathrm{P}=0.041)$.

Conclusions: According to the findings of the present study, distracting senses in snoezelen room decreases mother's pain intensity, the length of labor, and incidence of episiotomy.
\end{abstract}

Keywords: Snoezelen Room; Perinea Laceration; Childbirth; Labor Onset; Labor Pain

\section{Background}

Childbirth is a challenging and critical experience in women's life with its important psychological, sensational, and physical impact (1). The studies showed that fear of childbirth pain is a common feeling among pregnant women. The findings of a research conducted in Sweden, showed that at least $10 \%$ of women suffer from fear of labor. Negative impact of fear not only leads to adverse birth outcomes but also may increase the likelihood of cesarean section (2). Indeed, pain is a unique, complex, and personal experience with multiple responses to stimulation of the senses (3). The studies revealed that the main reason for cesarean operation is fear from childbirth pain. In Iran, episiotomy and fatigue are due to lack of tolerance for labor pain (4-6). In choosing strategies for coping with pain, fear, and fatigue, it is necessary to consider mother and baby's health.

Using techniques to increase comfort and reduce pain and stress of delivery is not a new concept. Currently, the complementary therapy is used to release the tension and relax the muscles of pregnant women with intense pain. Interventions to relieve sever pain often includes immersion in water (7), acupuncture and acupressure (8), transcutaneous electrical nerve stimulation (TENS)
(9), breathing techniques, yoga (10), hypnosis (11), physical and emotional support for coping with pain $(12,13)$, music therapy (14), listening to Quran, and massage therapy (15). Many researches have been already investigating on these interventions. A researcher reported various non-pharmacological methods for pain management with their proven effectiveness. Meanwhile, the efficacy of these interventions requires more investigation due to various limitations, which make the mother more dependent on her caregivers (16).

However, multi-sensory room offers a sense of safety and enhances the self-control behavior of the subjects. Ability to satisfy basic needs like eating, drinking, and so on will lead to more favorable results. For example, acupuncture is unpleasant for some due to fear of needle penetration. Also, acupuncture, acupressure, immersion in water, hypnosis, and TENS should be performed by a technically proficient practitioner (skilled in recognizing and determining trigger points) (17), while the participants of the present study could walk, eat, drink, and had opportunity to divert their attention to other things such as aquarium or optical motion pictures (18).

Controlled multi-sensory environment' or 'Snoezelen

Copyright (C) 2015, Iranian Red Crescent Medical Journal. This is an open-access article distributed under the terms of the Creative Commons Attribution-NonCommercial 4.0 International License (http://creativecommons.org/licenses/by-nc/4.0/) which permits copy and redistribute the material just in noncommercial usages, provided the original work is properly cited. 
room' is a Dutch term that means a room designed to stimulate the senses of people. History of snoezelen room dates back since the people had mild or severe disabilities. It provided muscles relaxation for the people who suffered from severe pain (19). This has become a part of complementary medicine, which promotes efficient comfort and relaxation causing endorphins release and relieving person's pain coping capacities. A snoezelen environment can be used as a distraction from pain by focusing on various senses, including visual and auditory. It provides participants with the feelings of comfort, relief, and self-control (20). Snoezelen term is the connection of two Dutch verbs 'snuffelen' (to seek out or explore) and 'doezelen' to relax (20). 'Multi-sensory environment' does not have a Persian translation; therefore, based on available literature we refer to it as 'Cave relaxation room.' The room design was a combination of light music, fish tank, optical illusions, and aromatic oils (19). A drop of lavender essence into some water of a dish had a candle. Release of endorphins help relieve the pain, relax the muscles (16), and divert the attention from the pain (17). The mechanism of effect of music on pain is as follows: the central part of the brain is specialized for attention, cognition, and emotional functions and nerve impulses go down to the posterior horn of the spinal cord, while music therapy impedes the transmission of nerve impulses to the spinal cord (15). The first snoezelen room was built in 1997 for treating children with serious and life-threatening conditions that suffered from pain (18). Controlled multi-sensory environment was used for treatment of people with disabilities too (19). It was aimed to provide an environment for relaxation through gentle stimulation and opportunities for interaction and reducing fatigue. A study evaluated the effect of snoezelen therapy on chronic pain management through the comparison of traditional treatment method with multisensory stimulation to promote relaxation. It showed significant reduction in pain intensity and fatigue during the first month of utilizing this method $(\mathrm{P}<0.03)(20)$. It seems necessary to provide this type of environment during childbirth process, which may reduce emotional stress of the mothers.

\section{Objectives}

The present study aimed to determine the effect of snoezelen room on the first and the second stages of delivery, labor pain intensity, perinea status, and number of cesarean operations.

\section{Patients and Methods}

This study was a randomized, controlled clinical trial. The study population included all eligible primiparous women admitted to the labor units in first stage of labor and had $4 \mathrm{~cm}$ of cervix dilation. Fifty subjects were allocated in each group. One of the rooms in hospital was de- signed as a snoezelen room (we called it 'seeking relaxation room'). There was an overhead projector emitting green light and different images. An aquarium with live fishes was placed there aimed to distract the patient's attention from the labor. Oil-burning candles were put in the room adding a drop of lavender essential oil (under supervision of the Ministry of Health) depending on the subject's request. A light music was being played, too (the song "Alone in the Rain"). Based on the guidelines used, the entire room was floored by soil-colored carpet (Figure 1).

The study was conducted at 2 birth rooms in one of the central state and educational hospitals affiliated to Iran University in Tehran, with approximately 600 monthly births.

The inclusion criteria were being primiparous with: 1 ) 4-cm dilated cervix; 2) intact membrane; 3) no indication for cesarean section; 4) no history of asthma, and allergy; 5) no pulmonary or heart diseases, high blood pressure, diabetes, or infertility; and 6) no cervical cerclage in the current pregnancy (21). After randomizing, the participants who underwent an emergency caesarean section were excluded. In the present study, the required sample size was estimated by a pilot study on 20 subjects to test the mean and standard deviation (SD) of the pain scores (VAS Scale) at 6 and $8 \mathrm{~cm}$ of cervical dilation. In the intervention and control groups, these pain scores were 6.04 $( \pm 1.10)$ and $7.59( \pm 1.49)$, respectively, which showed a difference of 1.55 in pain score between two groups. With statistical power of 0.8 and rejection of a null effect at 0.05 significant levels, we calculated that 38 subjects are needed in each group. Assuming a possible attrition rate of 35\%, the final target sample size was set at 50 per each group. The estimate attrition rate from the overall caesarean rate was $30 \%$ in state Iran Hospital(22). A convenience method was used for sampling. The study performed as a randomized controlled one, without blinding. Participants were randomly assigned to intervention (snoezelen room) and control groups. In order to evenly distribute the participants, a block randomization list (with block-sizes of 4 at 6 variation) was prepared by a statistician, and was given to two persons in reception unit in the form of sequentially numbered, sealed opaque envelopes, to provide concealment allocation to the group. The experimental group entered into snoezelen room where they could walk, sit, or lay down based on their wishes. Aquarium with fishes was placed in front of them at a distance of $1.5 \mathrm{~m}$ from the mothers and the projector with green light alternately changed pictures. The luminous shapes glinted to the wall. The lavender essence was dropped into water dish and a candle burned and evaporated into atmosphere. There was light music with sound rain. The mothers can walk, drink sweet liquids, and eat soft food. The control group received all that services except room design. It is not possible to blind both midwife and subjects to the intervention. As a research assistant, a qualified midwife working in that hospital serviced all 


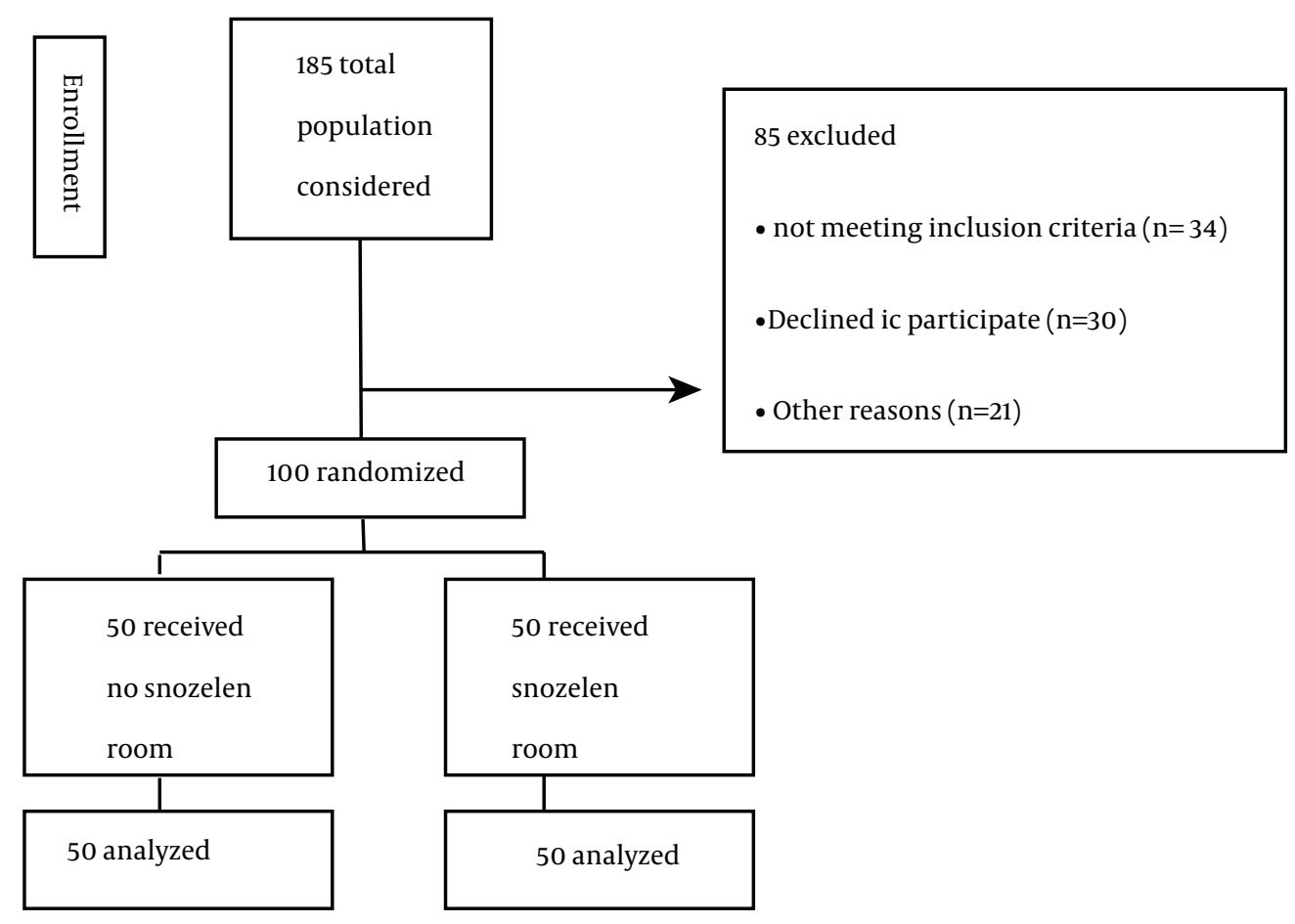

Figure 1. Consort Flow Diagram

participants of t2 groups. Pain intensity was measured using VAS Scale in both groups. Visual Analogue Scale (VAS) is a 10-cm horizontal line with a 'no pain at all' at the left end and 'worst possible pain' at the right end. Women indicated their level of pain intensity by placing a cross on the line (23). This scale is the standard scale that many researchers used (24-26). Pain was measured at entering the room, the first 3 hours (every hour), and in the second stage (from full dilation to onset of fetal head crowning). The first stage was measured from the mothers' entering to the room until full cervix dilation. The second stage was measured from full cervix dilation until the onset of fetal head crowning. Data were analyzed with SPSS version 16. Mann-Whitney test, Chi-square test and Independent $t$ test were conducted in statistical analyses. P values $<0.05$ were considered as significant. The study was performed for 10 months from December 2012 to May 2013.

\section{Results}

Fifty mothers were enrolled in each of experimental and control groups. The statistical analysis showed no significant difference with regard to age $(\mathrm{t}=1.43, \mathrm{P}=0.83$, $\mathrm{df}=85$ ), educational degree, job, and perinea status between the two groups. All mothers were housekeeper in the control group and $94 \%$ in experimental group. Perinea laceration occurred $92 \%$ in experimental group but $66 \%$ in the control group. The Chi-square analysis found significant differences in the perinea status (Table 1). The independent t test indicated significant difference between the mean score of two groups during the first stage, but did not show significant difference in the second stage. Using Independent t test, no significant difference was seen between the mean score of pain intensity in mothers when entering to labor, and during the first hour and the second hour, while significant difference was observed between the mean score of pain intensity in the third hour and in the second stage between two groups. The statistical analysis showed no significant difference in labor augmentation or newborns' Apgar score in the first minute (Table 2). None of the participants had childbirth by cesarean section method. Friedman test was used to match the samples for repeated data during that time and Wilcoxon pairs signed-rank test was used for pain intensity within groups. The results of Friedman test revealed a significant overall difference $(P<0.000)$. For paired comparison with Bonferroni correction, P value was 0.008. All paired comparisons were shown significant differences in sequential hours in the control group $(\mathrm{P}<0.000)$, which were expected. Because the process of cervix dilation was normal and accordingly pain was increasing. In intervention group, no significant difference was seen between pain intensity at the third hour with the first and the second hours. The result revealed that the intensity of pain in the intervention group increased less than that of the control group. 
Jamshidi Manesh Met al.

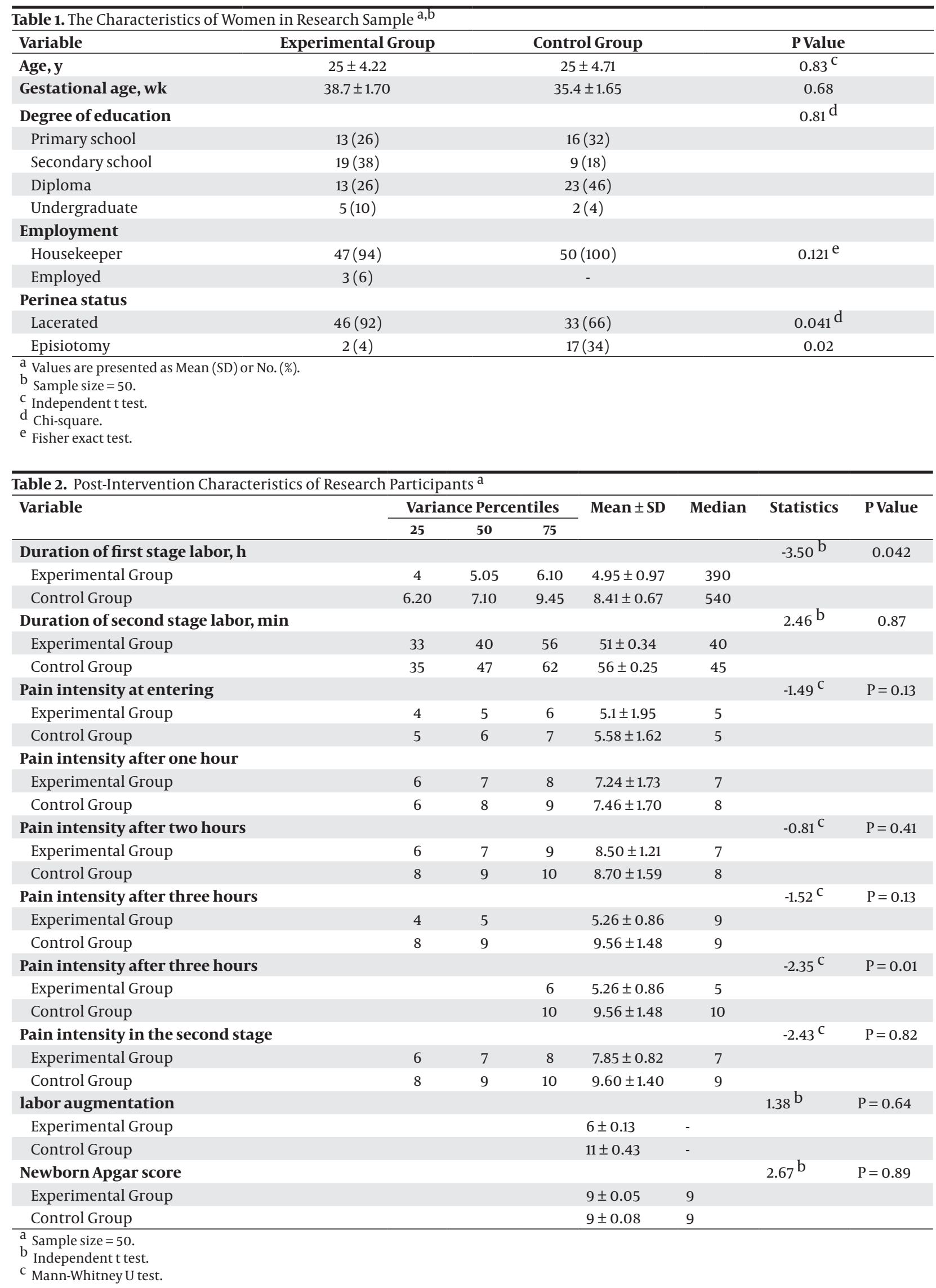




\section{Discussion}

The mean score of pain intensity at the third hour in the intervention and control groups were $5.26( \pm 0.86)$ and 9.56 ( \pm 1.48$)$, respectively. Another study reported that in the first three hours of active phase, the subjects reported pain intensity reduction in the intervention group compared to control group, but there was no difference in the subsequent hours between two groups (27). There were a significant difference in pain reduction following being in snoezelen room. It supports the pain-relieving effects of multi-sensory room, which used as a midwifery intervention for pain relieve in childbearing. This finding suggests that several factors are responsible in the relief of pain. Aromatherapy is one of the common elements in snoezelen room that increases the production of endorphins, decreases pain intensity, releases muscle tensions, and diverts attention from pain. The effect of music therapy is also one of the elements in snoezelen room. The central part of the brain is specialized for attention, cognition, and emotional functions and nerve impulses go down to the posterior horn of the spinal cord; in music therapy, transmission of nerve impulses to the spinal cord is impeded (16). Findings indicated that the first stage duration of labor in the intervention group was less than the control group and observed significant difference. Sosa showed that the length of time from mothers' admission to delivery was shorter in the experimental group compare to the control group ( 8.8 vs. 19.3 hours, $\mathrm{P}$ $<0.001$ ) without a supportive companion (27).

Induced pain in perinea by episiotomy is the cause of morbidity in postpartum. there are unpleasant consequences like insomnia, delayed in initial attachment between mother and newborn, and improper breast feeding position of mothers $(28,29)$. Evidence shows that the prevalence of perinea trauma is lower among women who gave birth at home, because they are mentally and physically are prepared for the birth and the environment is attractive and comfortable for the mother; so they get along with the physiological process, without hurrying, which creates a sense of security as home environment can help healthy perinea (30). It seems that snoezelen room has similar characteristics too.

The delivery process is controlled by providing calm and relaxed environment in hospital, undertaking maximum self-control ability, and increasing pressure in lower abdominal pressure to help easier delivery of fetus's head, so that childbirth would be implemented with minimum injury to perineum.

The present study had some advantages and limitations. According to the results of this study, there was less pain and shorter duration in the first labor phase in mothers staying in snoezelen room than the mothers without this facility. Therefore, snoezelen room may be an effective option for mother's satisfaction in childbearing and reduction in cesarean rate. Since pain relief occurred a couple of hours after entering to labor in our study, it seemed that those mothers did not have any ex- perience for childbirth in such places. It is better that the mothers got familiar with this type of delivery room in antenatal period. The limitation in our study was related to the different level of anxiety and fear in mothers entering the hospital. It is generally out of control of a responsible midwife. Childbirth is a stressful event, and anxiety and lower satisfaction are associated with a traumatic experience. Acute pain is often accompanied by anxiety and distress and almost all women experience it in childbirth $(31,32)$. Taking information about the procedure of hospital admission, genital anatomy, physical examinations, and laboratory tests can reduce anxiety and increase the sense of self-control over labor.

We did not study the effect of snoezelen room on multiparous mothers. It is better that these mothers be studied too.

The Ethics Committee of the Iran University approved the study. The researcher obtained the participants' consent from. All women were informed of the confidential nature of the data. They were also told that they were free to answer any questions or withdraw from the study at any time. All participants were encouraged to ask any questions or raise any concerns about their care or participation in the study.

\section{Acknowledgements}

Author would like to thank all the study participants. We kindly express our appreciation to Iran University of Medical Sciences.

\section{Authors' Contributions}

Mansoureh Jamshidi Manesh developed the original idea and guideline to do the project. Mahnaz Kalati helped mothers in their childbearing and collected the data. Fatemeh Hosseini analyzed the data.

\section{Funding/Support}

The research was funded by Research Vice Chancellor of Iran University of Medical Sciences. We kindly express our appreciation to Iran University of Medical Sciences.

\section{References}

1. Bertucci V, Boffo M, Mannarini S, Serena A, Saccardi C, Cosmi E, et al. Assessing the perception of the childbirth experience in Italian women: a contribution to the adaptation of the Childbirth Perception Questionnaire. Midwifery. 2012;28(2):265-74.

2. Adisasmita A, Deviany PE, Nandiaty F, Stanton C, Ronsmans C Obstetric near miss and deaths in public and private hospitals in Indonesia. BMC Pregnancy Childbirth. 2008;8:10.

3. Waldenstrom U, Hildingsson I, Ryding EL. Antenatal fear of childbirth and its association with subsequent caesarean section and experience of childbirth. BJOG. 2006;113(6):638-46.

4. Johanson R, Newburn M, Macfarlane A. Has the medicalisation of childbirth gone too far? BMJ. 2002;324(7342):892-5.

5. Jamshidi Manesh M, Jouybari L, Oskouie F, Sanagoo A. How do Women's Decisions Process to Elective Cesarean?: A Qualitative Study. Australian J of Basic and Applied Sci. 2011;5(6):210-5.

6. Moradan S. Evaluation of selection of route of delivery and it's causes in partient referring to medical centers of Semnan from 
April till September 2004. Iranian Journal of Obstetrics, Gynecology and Infertility. 2005;7(2):44-9.

7. Cluett ER, Nikodem VC, McCandlish RE, Burns EE. Immersion in water in pregnancy, labour and birth. Cochrane Database Syst Rev. 2004(2):CD000111.

8. Cho SH, Lee H, Ernst E. Acupuncture for pain relief in labour: a systematic review and meta-analysis. BJOG. 2010;117(8):907-20.

9. Bewley S, Cockburn J. Responding to fear of childbirth. Lancet. 2002;359(9324):2128-9.

10. Chuntharapat S, Petpichetchian W, Hatthakit U. Yoga during pregnancy: effects on maternal comfort, labor pain and birth outcomes. Complement Ther Clin Pract. 2008;14(2):105-15.

11. Abbasi M, Ghazi F, Barlow-Harrison A, Sheikhvatan M, Mohammadyari F. The effect of hypnosis on pain relief during labor and childbirth in Iranian pregnant women. Int J Clin Exp Hypn. 2009;57(2):174-83.

12. Stevens NR, Wallston KA, Hamilton NA. Perceived control and maternal satisfaction with childbirth: a measure development study.J Psychosom Obstet Gynaecol. 2012;33(1):15-24.

13. Copstick SM, Taylor KE, Hayes R, Morris N. Partner support and the use of coping techniques in labour. J Psychosom Res. 1986;30(4):497-503.

14. Mertens K. Snoezelen: Sensory Stimulation and Relaxation in special interior rooms.Portugal:Acedido; 2004.

15. Schofield P. Snoezelen: its potential for people with chronic pain. Complement Ther Nurs Midwifery. 1996;2(1):9-12.

16. Nasser K, Cahana C, Kandel I, Kessel S, Merrick J. Snoezelen: children with intellectual disability and working with the whole family. ScientificWorldJournal. 2004;4:500-6.

17. Stevensen C. The psychophysiological effects of aromatherapy massage following cardiac surgery. Complementary Therapies in Medicine. 1994;2(1):27-35.

18. Hope KW, Waterman HA. Waterman Using Multi-Sensory Environments (MSEs) with People with Dementia. Dementia. 2004;3(1):45-68.

19. Schofield PA, Davis BD, Hutchinson R. Snoezelen and chronic pain: developing a study to evaluate its use (Part I). Complement Ther Nurs Midwifery. 1998;4(3):66-72.

20. Schofield P, Davies B, Hutchinson R. Evaluating the use of Snoezelen and chronic pain: the findings of an investigation into its use (Part II). Complementary Therapies in Nursing and Midwifery. 1998;4(5):137-43.

21. Albers LL. The evidence for physiologic management of the active phase of the first stage of labor. J Midwifery Womens Health. 2007;52(3):207-15.

22. Islamic Republic News Agency.. cesarean rate in Tehran, Iran.: Islamic Republic News Agency;. Available from: http://www.irna.ir/ fa/News/81210748.

23. Melzack R, Belanger E, Lacroix R. Labor pain: effect of mater nal position on front and back pain. J Pain Symptom Manage. 1991;6(8):476-80.

24. Salekzamani Y, Mirzaee S, Shakouri SK, Nezami N. Pain relieving effect of thermoplastic lumbosacral orthosis with adjustable posterior pad in chronic non-specific low back pain. Iran Red Crescent Med J.2011;13(12):903-5.

25. Aman Elahi AA, Helisaz MT, Shams Aldini AR. Comparison of effectiveness of Acupuncture and oral Piroxicam on pain and daily living activity of mechanical chronic low back pain patients. Kowsar Med J. 2010;4(4).

26. Kordi M, Firoozi M, Esmaili H. Effect of LI4 acupressure on labor pain in the first stage of labor in nuliparous women. Hayat. 2011;16(3):95-101.

27. Phumdoung S, Good M. Music reduces sensation and distress of labor pain. Pain Manag Nurs. 2003;4(2):54-61.

28. Sosa R, Kennell J, Klaus M, Robertson S, Urrutia J. The effect of a supportive companion on perinatal problems, length of labor, and mother-infant interaction. N Engl J Med. 1980;303(11):597600.

29. Kalichman L. Perineal massage to prevent perineal trauma in childbirth. Isr Med Assoc J. 2008;10(7):531-3.

30. Dodd JM, Hedayati H, Pearce E, Hotham N, Crowther CA. Rectal analgesia for the relief of perineal pain after childbirth: a randomised controlled trial of diclofenac suppositories. BJOG. 2004;111(10):1059-64.

31. Lindgren HE, Brink A, Klinberg-Allvin M. Fear causes tears - perineal injuries in home birth settings. A Swedish interview study. BMC Pregnancy Childbirth. 2011;1:6.

32. Cheung W, Ip WY, Chan D. Maternal anxiety and feelings of control during labour: a study of Chinese first-time pregnant women. Midwifery. 2007;23(2):123-30. 